Proceedings

\title{
Conversion of Solid Biomass into Biochar: Act as a Green, Eco-Friendly Energy Source and a Substitute of Fossil Fuel Inputs ${ }^{+}$
}

\author{
Swapan Suman ${ }^{1,2}$ \\ 1 Department of Mechanical Engineering, Meerut Institute of Engineering \& Technology, \\ Meerut 250005, Uttar Pradesh, India; er.ssuman@gmail.com or swapan.suman@miet.ac.in \\ 2 Department of Fuel \& Mineral Engineering, IIT (ISM) Dhanbad, Dhanbad 826004, Jharkhand, India \\ + Presented at the First World Energies Forum, 14 September-5 October 2020; \\ Available online: https://wef.sciforum.net/. \\ Published: 11 September 2020
}

\begin{abstract}
To meet the global demand of energy requires an alternative source, preferably with a lower concern of climate change. Biochar production from agricultural biomass waste by pyrolysis creates a unique solution for producing a useful source of green energy. Biochar is a carbon-rich product with a high heating value which is comparable with our primary energy sources (fossil fuels). Biochar can be utilized for various purposes such as energy production and soil enhancement. Biochar can be more suitable for steelmaking, in view of their chemical and thermo-chemical characteristics including low ash, higher heating values (HHV), and high surface area. Biochar can also be utilised selectively for soil amelioration, C-sequestration, and waste water treatment, in view of the suitability of their characteristics (such as higher values of $\mathrm{pH}$, mineral content, and surface area) for meeting the requirements for a particular purpose. This study associates the characteristics of biochar produced by slow pyrolysis at $800{ }^{\circ} \mathrm{C}$ for two biomass residues: corn cob and coconut shell. These results can be used to establish ideal utilization means of biomass for energy and/or biochar production.
\end{abstract}

Keywords: agricultural biomass waste materials; biochar; slow pyrolysis; heating value; surface area

\section{Introduction}

Among the various renewable energy sources, biomass has the potential to be used as an alternative source of energy [1] that is $\mathrm{CO}_{2}$-neutral [2]. There is a need to convert the biomass into such a form that will go beyond all these related aspects with potential utilisation for various productive purposes, such as energy production and climate change mitigation [3]. Pyrolysis among the green technologies that produce energy from biomass [4]. Biochar is recognized as a very significant tool of environmental management [5]. Biochar is a new technical term. According to Lehmann and Joseph [5], it is defined as "a carbon (C)-rich product". Shackley et al. [6] defined biochar more descriptively as "the porous carbonaceous solid product". Verheijen et al. [7] also defined biochar as "biomass that has been pyrolyzed in a zero or low oxygen environment applied to soil at a specific site". All of these definitions are directly or indirectly related to the biochar production and its potential application. The fast depletion of high-grade coking coal reserves and the negative impact of fossil fuels on the environment calls for the use of renewable and alternate clean source of energy. Biochars is a carbon-rich product derived from pyrolysis of solid biomass wastes, and their utilisation potential is increasing the interest in the beneficial applications in 
carbon sequestration, soil fertility improvement, pollution remediation, waste water treatments, thermal and metallurgical purposes, iron and steel industry, etc.

Biomass is a green renewable source of carbon, and using it to produce biochar can release energy with virtually no sulphur and a very small amount of nitrogen [8]. Producing biochar from biomass waste appears to be a promising method of achieving greater levels of inevitability and flexibility for integrating the enhancement of carbon and soil fertility [9]. The application of biochar receives attention for its improvement of soil quality and carbon sequestration [10,11]. In the soil, biochar increases the soil holding water capacity and nutrients, reducing the need for fertilizers. Biochar contains carbon, which can directly store for a long time due to its strong resistance to biological decomposition [12,13]. Biochar has high energy and is rather comparable to the coal used in the industries as feed stocks for fuel $[14,15]$.

Hence, the objective of present study was to gain an insight into the characteristics of the biochars and evaluate their potential of utilisation.

\section{Materials and Methods}

\subsection{Sample Collection and Preparation}

Corn Cob (CC) and Coconut Shell (CS) were collected from the local area of Dhanbad, Jharkhand, India. These samples were ground to below $0.5 \mathrm{~mm}$, dried in an air-oven at $60{ }^{\circ} \mathrm{C}$ for 24 $\mathrm{h}$, and pyrolyzed [16] in muffle furnace at temperature $800^{\circ} \mathrm{C}$ with heating rate of $5-10^{\circ} \mathrm{C} / \mathrm{min}$. The carbonized products were then grounded to a particle size of below 212 microns (-72 mesh) and further characterized for their biochar properties.

\subsection{Proximate and Ultimate Analysis}

To conduct the proximate analysis followed under standard methods ASTM E871-82, E1755-01, and E872-82 [16] for CC and CS and standard method ASTM D1762-84 [16] for corn cob char (CC ch) and coconut shell char ( $\mathrm{CS}_{\mathrm{ch}}$ ), the fixed carbon (FC) content was calculated by difference.

ASTM E777, 778, and 775 standard test methods were followed for ultimate analysis [17] in order to determine the basic elemental composition [18] of all the samples using a Vario El III CHNS (Carbon, Hydrogen, Nitrogen and Sulfur) analyser.

\subsection{Gross Calorific Value (Heating Value) and Surface Area}

The gross calorific values of all the samples were determined by bomb calorimeter (T-451, TESTMASTER, Kolkata, India) followed by the standard method (ASTM D4809-00) [19].

The surface area was determined using $\mathrm{N}_{2}$ sorption isotherms using the Brunauer-EmmettTeller (ASA P2020 BET, Downers Grove, IL, USA) Surface Area Analyzer [20].

\section{Results and Discussion}

\subsection{Proximate and Ultimate Analyses CC, CS, $C C_{c h}$, and $C S_{c h}$}

Proximate and ultimate analyses of CC, CS, CC ch, and $\mathrm{CS}_{\mathrm{ch}}$ are shown in Table 1. The volatile matter of CC and CS were found to be on the higher side-i.e., 76.18 and $79.23 \%$, respectively, in comparison to their corresponding char. Volatile Matter (VM) content of biomass decreases with pyrolysis because the presence of lignin in the biomass waste feedstocks cannot resist the pyrolytic decomposition at temperatures as high as $800{ }^{\circ} \mathrm{C}$ [21]. 
Table 1. Characterization of the samples.

\begin{tabular}{|c|c|c|c|c|}
\hline \multirow[b]{2}{*}{ * Characterization } & \multicolumn{4}{|c|}{ Samples } \\
\hline & $\begin{array}{l}\text { Corn Cob } \\
\text { (CC) }\end{array}$ & $\begin{array}{l}\text { Coconut Shell } \\
\text { (CS) }\end{array}$ & $\begin{array}{c}\text { Corn Cob Char } \\
\left(\mathrm{CC}_{\mathrm{ch}}\right)\end{array}$ & $\begin{array}{c}\text { Coconut Shell Char } \\
\left.\text { (CS } \text { ch }_{\text {ch }}\right)\end{array}$ \\
\hline Moisture\% & 3.20 & 2.11 & 3.45 & 3.54 \\
\hline Ash \% & 4.66 & 1.09 & 5.67 & 3.77 \\
\hline Volatile Matter\% & 76.18 & 79.23 & 12.33 & 13.45 \\
\hline Fixed Carbon \% & 15.96 & 17.57 & 78.55 & 81.24 \\
\hline Carbon $\%$ & 45.90 & 50.10 & 81.23 & 84.62 \\
\hline Hydrogen \% & 5.58 & 6.74 & 3.24 & 2.11 \\
\hline Nitrogen $\%$ & 0.75 & 0.35 & 0.33 & 0.28 \\
\hline Sulfur\% & 0.06 & 0.07 & 0.03 & 0.05 \\
\hline Oxygen $\%$ & 41.95 & 38.67 & 15.17 & 12.94 \\
\hline $\begin{array}{c}\text { Gross Calorific Value } \\
(\mathrm{MJ} / \mathrm{Kg})\end{array}$ & 18.24 & 20.40 & 23.56 & 28.63 \\
\hline Surface Area $\left(\mathrm{m}^{2} \mathrm{~g}^{-1}\right)$ & - & - & 297.76 & 434.66 \\
\hline
\end{tabular}

* All parameters are on a received basis.

From ultimate analysis data, it can be observed that the principal components [22] such as, $\mathrm{C}, \mathrm{H}$, $\mathrm{N}, \mathrm{S}$, and $\mathrm{O}$, differed in both cases (biomass and its corresponding biochars). The higher the content of VM and FC in CS, the higher the content of C and H in CS than in CC. The carbon contents of obtained biochars are 74.54 and $79.31 \%$ for $\mathrm{CC}_{\mathrm{ch}}$ and $\mathrm{CS}_{\mathrm{ch}}$, respectively. Among all these elements, the contribution of carbon was highest in most of the biochars [23], which was followed by oxygen, then hydrogen and then the rest of the components, although the compositions of nitrogen and sulphur content in biochar materials are low or approximately same.

\subsection{Gross Calorific Value (GCV) and Surface Area}

Gross Calorific Value (GCV) and surface area of the biochars are shown in Table 1. The biochars-i.e., $\mathrm{CC}_{\mathrm{ch}}$ and $\mathrm{CS}_{\mathrm{ch}}-$ had a higher heating value (Gross Calorific Value) than the raw biomass-i.e., CC and CS [21]. This may be because the carbon content increases in biochar with pyrolysis. The presence of these $\mathrm{C}, \mathrm{H}$, and $\mathrm{O}$ elements in biomass led to more char formation as well as to the higher heating value of the product. The GCV for CC, CS, CC $\mathrm{ch}_{\mathrm{c}}$, and $\mathrm{CS}_{\mathrm{ch}}$ varied in the range 18.24, 20.40, 23.56, and 28.63 MJ/Kg, respectively. Similarly, Brunauer-Emmett-Teller (BET) surface area varied in the range 297.76 and $434.66 \mathrm{~m}^{2} \mathrm{~g}^{-1}$, for $\mathrm{CC}_{\mathrm{ch}}$ and $\mathrm{CS}_{\mathrm{ch}}$, respectively, which is in agreement with the observations of others $[21,24,25]$.

Biochars have pore-blocking substances, which are driven off or thermally cracked, leading to enhancement in the surface area and its pore volume [26]. The more typical of these biomasses have high content of VM, thereby the derived biochars have a high specific surface area [27].

\section{Utilization Potential for Green Energy and Enhancement of Soil Fertility}

The potential of utilisation for Green Energy and Enhancement for Soil Fertility depends on the characteristics of the biochars. Accordingly, obtained biochars of CC and CS with targeted physicochemical properties are essential $[28,29]$.

Considering the result obtained, efforts need to be made to obtain biochar with a good relation between its properties and reducing environmental costs with relatively less energy consumption [28-32]. The conversion process appears to be a potential option to utilise these biomass wastes for sustainable purposes including as a substitute of green energy sources. In this structure, it is germane to mention that the volatile matter content of most of these biochars at $\geq 650{ }^{\circ} \mathrm{C}$ falls within the range $10-40 \mathrm{wt} \%$ used for the steelmaking industry [33], also considering the other various parameters such as higher content of FC, C, GCV, and surface area.

These biochar materials with a significant surface area $\left(297.76\right.$ and $\left.434.66 \mathrm{~m}^{2} \mathrm{~g}^{-1}\right)$ are also evocative of their better application potential in improving the soil-attributable cation exchange 
capacity (CEC), and treating the soil and water contaminated with toxic elements and organic pollutants [34-36].

\section{Conclusions}

Biochar produced from the pyrolysis of corn cob and coconut shell biomass samples at $800{ }^{\circ} \mathrm{C}$ had different physical and chemical properties. Obtained biochars from these wastes have higher content of volatile matter, fixed carbon, $\mathrm{C}, \mathrm{H}$, and higher heating value-i.e., gross calorific value. This conversion of wastes from pyrolysis to biochar can be a potential substitute for fossil-derived fuel (coal, oil, etc.) to green renewable energy sources such as: for steel making, as a soil ameliorant, enhance soil fertility, C-sequestration, and also in waste water handling.

Funding: This research received no external funding.

Conflicts of Interest: The authors declare no conflict of interest.

\section{References}

1. Protasio, T.D.P.; Junior, M.G.; Mirmehdi, S.; Trugilho, P.F.; Napoli, A.; Knovack, K.M. Combustion of biomass and charcoal made from babassu nutshell. Cerne 2017, 23, 1-10.

2. Tinwala, F.; Mohanty, P.; Parmar, S.; Patel, A.; Pant, K.K. Intermediate pyrolysis of agro-industrial biomasses in bench-scale pyrolyser: Product yields and its characterization. Bioresour. Technol. 2015, 188, 258-264.

3. Barrow, C.J. Biochar: Potential for countering land degradation and for improving agriculture. Appl. Geogr. 2012, 34, 21-28.

4. Cser, H.; Boby, L. Technologies That Produce Electricity, Heat, and Fuel from Biomass Feedstocks; Integrated Biomass Supply Systems (IBSS): Knoxville, TN, USA, 2015; pp. 1-4.

5. Lehmann, J.; Joseph, S. Biochar for environmental management: An introduction. In Biochar for Environmental Management Science and Technology; Lehmann, J., Joseph, S., Eds.; Earthscans: London, UK, 2009; pp. 1-12.

6. Shackley, S.; Carter, S.; Knowles, T.; Middelink, E.; Haefele, S.; Sohi, S.; Cross, A.; Haszeldine, S. Sustainable gasification-biochar systems? A case-study of rice-husk gasification in Cambodia, Part 1: Context, chemical properties, environmental and health and safety issues. Energy Policy 2012, 42, 49-58.

7. Verheijen, F.; Jeffery, S.; Bastos, A.C.; Van Der Velde, M.; Diafas, I. Biochar Application to Soils: A Critical Scientific Review of Effects on Soil Properties. Processes and Functions; European Commission: Ispra, Italy, 2010.

8. Verma, M.; Godbout, S.; Brar, S.K.; Solomatnikova, O.; Lemay, S.P.; Larouche, J.P. Biofuels Production from Biomass by Thermochemical Conversion Technologies. Int. J. Chem. Eng. 2012, 2012, 542426.

9. Lehmann, J. Bio-energy in the black. Front. Ecol. Environ. 2007, 5, 381-387.

10. Woolf, D.; Amonette, J.E.; Perrott, F.A.S.; Lehmann, J.; Joseph, S. Sustainable biochar to mitigate global climate change. Nat. Commun. 2010, 1, 56.

11. Sohi, S.P. Carbon storage with benefits. Science 2012, 338, 1034-1035.

12. Liang, B.; Lehmann, J.; Solomon, D.; Sohi, S.; Thies, J.E.; Skjemstad, J.O.; Luizão, F.J; Engelhard, M.H.; Neves, E.G.; Wirick, S. Stability of biomass derived black carbon in soils. Geochim. Cosmochim. Acta 2008, 72, 6069-6078.

13. Lee, Y.; Park, J.; Ryu, C.; Gang, K.S.; Yang, W.; Park, Y.K.; Jung, J.; Hyun, S. Comparison of biochar properties from biomass residues produced by slow pyrolysis at $500^{\circ} \mathrm{C}$. Bioresour. Technol. 2013, 148, 196201.

14. Fu, P.; Hu, S.; Xiang, J.; Sun, L.; Su, S.; Wang, J. Evaluation of the porous structure development of chars from pyrolysis of rice straw: Effects of pyrolysis temperature and heating rate. J. Anal. Appl. Pyrolysis 2012, 98, 177-183.

15. Mohanty, P.; Pant, K.K.; Naik, S.N.; Parikh, J.; Hornung, A.; Sahu, J.N. Synthesis of green fuels from biogenic waste through thermochemical route-The role of heterogeneous catalyst: A review. Renew. Sustain. Energy Rev. 2014, 38, 131-153.

16. Suman, S.; Gautam, S. Effect of pyrolysis time and temperature on the characterization of biochars derived from biomass. Energy Sources Part A Recovery Util. Environ. Eff. 2017, 39, 933-940. 
17. Mena, H.L.E.; Pecora, A.A.B.; Beraldo, A.L. Slow Pyrolysis of Bamboo biomass: Analysis of Biochar properties. Chem. Eng. Trans. 2014, 37, 115-120.

18. Couto, A.M.; Protásio, T.D.P.; Trugilho, P.F.; Neves, T.A.; Sa, V.A.D. Multivariate analysis applied to evaluation of Eucalyptus clones for bioenergy production. Cerne 2013, 19, 525-533.

19. Gupta, O.P. Fuels, Furnaces and Refractory, 1st ed.; Khanna Publication: Delhi, India, 1990.

20. Zhang, G.; Zhang, O.; Sun, K.; Liu, X.; Zheng, W.; Zhaoil, Y. Sorption of simazine to corn straw biochars prepared at different pyrolytic temperatures. Environ. Pollut. 2011, 159, 2594-2601.

21. Jindo, K.; Mizumoto, H.; Sawada, Y.; Monedero, M.A.S.; Sonoki, T. Physical and chemical characterization of biochars derived from different agricultural residues. Biogeosciences 2014, 11, 6613-6621.

22. Tao, G.; Lestander, T.A.; Geladi, P.; Xiong, S. Biomass properties in association with plant species and assortments I: A synthesis based on literature data of energy properties. Renew. Sustain. Energy Rev. 2012, 16, 3481-3506.

23. Purevsuren, B.; Avid, B.; Tesche, B.; Davaajav, A.Y. Biochar from Casein and Its Properties. J. Mater. Sci. 2003, 38, 2347-2351.

24. Aziz, S.; Yaseen, L.; Jamal, A.; Farooq, U.; Qureshi, Z.; Tauseef, I.; Haleem, S.K.; Ali, M.I. Fabrication of Biochar from Organic Wastes and its Effect on Wheat Growth and Soil Microflora. Pol. J. Environ. Stud. 2020, 29, 1069-1076.

25. Peng, X.; Ye, L.L.; Wang, C.H.; Zhou, H.; Sun, B. Temperature and duration-depend rice straw-derived biochar: Characteristics and its effects on soil properties of an Untisol in southern China. Soil Tillage Res. 2011, 112, 159-166.

26. Rafiq, M.K.; Bachmann, R.T.; Rafiq, M.T.; Shang, Z.; Joseph, S.; Long, R. Influence of Pyrolysis Temperature on Physico-Chemical Properties of Corn Stover (Zea mays L.), Biochar and Feasibility for Carbon Capture and Energy Balance. PLoS ONE 2016, 11, e156894, doi:10.1371/journal.pone.0156894.

27. Vassilev, S.; Baxter, D.; Andersen, L.; Vassileva, C. An overview of the composition and application of biomass ash. Part 2. Potential utilization, technological and ecological advantages and challenges. Fuel 2013, 105, 19-39.

28. Veksha, A.; Mclaughlin, H.; Layzell, D.B.; Hill, J.M. Pyrolysis of wood to biochar: Increasing yield while maintaining microporosity. Bioresour. Technol. 2014, 153, 173-179.

29. Mukherjee, A.; Zimmerman, A.R.; Harris, W. Surface chemistry variations among a series of laboratory-produced biochars. Geoderma 2011, 163, 247-255.

30. Wabel, M.I.A.; Omran, A.A.; Naggar, A.H.E.; Nadeem, M.; Usman, A.R.A. Pyrolysis temperature induced changes in characteristics and chemical composition of biochar produced from conocarpus wastes. Bioresour. Technol. 2013, 131, 374-379.

31. Luo, L.; Xu, C.; Chen, Z.; Zhang, S. Properties of biomass-derived biochars: Combined effects of operating conditions and biomass types. Bioresour. Technol. 2015, 192, 83-89.

32. Enders, A.; Hanley, K.; Whitman, T.; Joseph, S.; Lehmann, J. Characterization of biochars to evaluate recalcitrance and agronomic performance. Bioresour. Technol. 2012, 11, 4644-4653.

33. Ahmad, M.; Rajapaksha, A.U.; Lim, J.E.; Zhang, M.; Bolan, N.; Mohan, D.; Vithanage, M.; Lee, S.S.; Ok, Y.S. Biochar as a sorbent for contaminant management in soil and water: A review. Chemosphere 2014, 99, 1933.

34. Chen, B.; Zhou, D.; Zhu, L. Transitional adsorption and partition on nonpolar and polar aromatic contaminants by biochars of pine needles with different pyrolytic temperatures. Environ. Sci. Technol. 2008, 42, 5137-5143.

35. Kloss, S.; Zehetner, F.; Dellantonio, A.; Hamid, R.; Ottner, F.; Liedtke, V.; Schwanninger, M.; Gerzabek, M.H.; Soja, G. Characterization of slow pyrolysis biochars: Effects of feedstocks and pyrolysis temperature on biochar properties. J. Environ. Qual. 2012, 41, 990-1000.

36. Medynska-Juraszek, A.; Ćwielag-Piasecka, I. Effect of Biochar Application on Heavy Metal Mobility in Soils Impacted by Copper Smelting Processes. Pol. J. Environ. Stud. 2020, 29, 1749-1757.

(C) 2020 by the authors. Licensee MDPI, Basel, Switzerland. This article is an open access article distributed under the terms and conditions of the Creative Commons Attribution (CC BY) license (http://creativecommons.org/licenses/by/4.0/). 